\title{
EVALUASI PENGELOLAAN BANK SAMPAH DI KOTA MOJOKERTO
}

Umrotul Malikah ${ }^{1}$, Darjati ${ }^{2}$, Demes Nurmayanti ${ }^{3 *}$

${ }^{1}$ Dinas Kesehatan Kota Mojokerto

2,3 Poltekkes Kemenkes Surabaya

*Email korespondensi: demes.poltekkes@gmail.com

\begin{abstract}
ABSTRAK
Pengelolaan sampah merupakan salah satu masalah yang perlu diprioritaskan dalam menjaga kelestarian lingkungan perkotaan. Tempat Pembuangan Akhir (TPA) Randegan Kota Mojokerto tidak mampu menampung volume sampah, salah satunya dengan melaksanakan kegiatan Bank Sampah berdasarkan Undang-Undang Nomor 18 Tahun 2008 tentang Pengelolaan Sampah. Tujuan dari penelitian ini adalah untuk mengevaluasi perencanaan, pengorganisasian, pelaksanaan, dan pengawasan pengelolaan bank sampah di Kota Mojokerto.

Penelitian ini menggunakan pendekatan deskriptif kualitatif dengan teknik wawancara, observasi lapangan dan Penelusuran Dokumen. Data tersebut dikelompokkan berdasarkan faktor lingkungan internal dan eksternal yang ada pada bank sampah di 3 (tiga) kecamatan di Kota Mojokerto yang berjumlah 25 bank sampah. Data yang diperoleh dianalisis menggunakan SWOT.

Hasil penelitian menunjukkan bahwa faktor kekuatan sebesar 1,316, kelemahan sebesar 1,361, peluang sebesar 1.730, dan ancaman sebesar 1.1471. Selisih skor total faktor Kekuatan dan Kelemahan (-) sebesar 0,045. Selisih skor total faktor Opportunity and Treath (+) sebesar 0,583. Posisi di Kuadran III berarti organisasi berada pada posisi yang lemah tetapi memiliki banyak peluang. Strategi yang harus diterapkan dalam pengelolaan bank sampah di Kota Mojokerto adalah Strategi WO (Weakness-Opportunity), merupakan kombinasi faktor kelemahan internal dengan faktor peluang eksternal.
\end{abstract}

Kata kunci : Pengelolaan bank sampah, SWOT

\section{PENDAHULUAN}

Pengelolaan sampah perkotaan menjadi isu krusial bagi wilayah perkotaan, mengingat kurangnya sarana prasarana pengumpulan, pengangkutan, perlakuan dan pembuangan sampah dalam jumlah besar. Pengelolaan sampah yang tidak tepat dan berdampak buruk terhadap kehidupan dan kesehatan manusia. Pengelolaan sampah menjadi salah satu problem yang perlu diprioritaskan didalam melestarikan lingkungan hidup perkotaan (Thanh et al., 2010z; 2011). Pada peningkatan jumlah sampah perkotaan tidak diimbangi dengan upaya pengelolaan serta sarana prasarana yang memadai sehingga penanganan sampah dilakukan secara open dumping di Tempat Pembuangan Akhir (TPA). Penanganan dengan cara ini akan membutuhkan lahan seluas $1610 \mathrm{~m}^{2}$ pada tahun 2020 (Zakianis et al.,2018).

Seperti halnya TPA Randegan Kota Mojokerto yang hanya memiliki luas lahan 2,5 Ha. Semula melakukan pengolahan sampah dengan sistem open dumping berubah menjadi sanitary landfill, tetapi masih belum maksimal dalam menampung volume sampah. Sehingga perlu ada gerakan pengembagan pengelolaan sampah melalui Bank Sampah ditingkat RT/RW setempat. Gerakan pengelolaan sampah dapat dilakukan melalui organisasi kemasyarakatan seperti karang taruna dan PKK. Oleh karena itu perlu adanya sosialisasi bank sampah yang dilakukan oleh pihak terkait pada masyarakat agar masyarakat lebih paham dan mengerti betapa pentingnya diadakan bank sampah. Sosialisasi yang dilakukan bisa berupa penyuluhan dan atau seminarseminar yang dilakukan disetiap kelurahan.

Pengelolaan Bank Sampah juga mengikuti kaidah yang terdapat dalam Undang-Undang Nomor 18 Tahun 2008 tentang Pengelolaan Sampah, bahwa prinsip dalam mengelola sampah adalah 
Reduce, Reuse dan Recycle (3R). Bank Sampah merupakan salah satu strategi dan solusi untuk membangun kepedulian masyarakat agar dapat peduli dengan sampah sehingga mendapatkan manfaat ekonomi langsung dari sampah.

Pengelolaan sampah berbasis masyarakat melalui Bank Sampah, disosialisasikan oleh Dinas Lingkungan Hidup (DLH) Kota Mojokerto sejak tahun 2010 kepada masyarakat agar membentuk Bank Sampah di tingkat RW, karena Kota Mojokerto mempunyai lahan yang terbatas yaitu hanya sebesar $20 \mathrm{~km}^{2}$ dengan jumlah penduduk terpadat sebanyak 139.423 jiwa pada tahun 2019.

Jumlah Bank Sampah terus meningkat hingga jumlahnya terus berkembang walau belum mencapai $100 \%$ dari 180 RW yang ada. Berdasarkan data dari Dinas Lingkungan Hidup sampai dengan bulan Maret 2020 jumlah bank sampah sebanyak 145 unit dan hanya tersebar di 127 RW. Jumlah ini masih belum mencapai target waktu yang ditentukan yakni tahun 2018, seharusnya semua RW sudah terbentuk Bank Sampah.

Pemerintah Kota Mojokerto melalui Dinas Lingkungan Hidup telah membentuk Bank Sampah Induk (BSI) pada tahun 2016, pada saat itu nama Organisasi Pemerintah Daerah (OPD) masih bernama Kantor Lingkungan Hidup (KLH) yang sekarang menjadi DLH. BSI dibentuk berdasarkan Keputusan Kepala Kantor Lingkungan Hidup (KLH) Kota Mojokerto nomor 188.45/202/417.111/2016 dan saat ini sedang dalam proses meningkatkan legalitas dalam bentuk Akte Berbadan Hukum dari Notaris.

Dengan sistem pengelolaan sampah ini diharapkan tidak ada lagi sampah yang berserakan di lingkungan. Volume sampah di TPA jumlahnya menjadi berkurang, karena sampah kering khususnya sudah dikelola oleh Bank Sampah, sehingga TPA hanya tinggal residu sampah dan sampah organik yang bisa dikelola menjadi kompos. Dengan demikian harapannya Kota Mojokerto dapat mewujudkan bebas sampah (zero waste) tahun 2019, namun sampai dengan saat itu tujuan tersebut belum dapat terwujud. Tujuan penelitian ini adalah mengevaluasi perencanaan, pengorganisasian, pelaksanaan, dan pengawasan pengelolaan bank sampah di Kota Mojokerto.

\section{METODE PENELITIAN}

Metode yang digunakan adalan observasional analitik, yang menjelaskan keadaan atau situasi pengembangan pengelolaan Bank Sampah di 25 Bank Sampah yang tersebar pada 3 (tiga) kecamatan yaitu kecamatan Magersari, Kecamatan Prajuritkulon dan Kecamatan Kranggan Kota Mojokerto.

Variabel yang diteliti tentang manajemen pengelolaan bank sampah meliputi Perencanaan, Pengorganisasian, Pelaksanaan, dan Pengawasan berdasarkan Peraturan Menteri Negara Lingkungan Hidup Republik Indonesia Nomor 13 tahun 2012. Teknik yang digunakan adalah teknik Observasi, Wawancara dan Penelusuran Dokumen. Data yang diperoleh dinarasikan secara kualitatif dengan menggunakan analisis SWOT yaitu penilaian Strenghts, Weakness, Opportunities dan Threaths. Analisis SWOT bertujuan untuk memaksimalkan kekuatan (strengths) dan peluang (opportunities), namun dapat meminimalkan kelemahan (weakness) dan ancaman (threaths).

\section{HASIL DAN PEMBAHASAN Perencanaan Pengelolaan Bank Sampah}

Sebagian besar bank sampah termasuk dalam kategori tidak sesuai, sehingga harus dilakukan perbaikan pada indikator perencanaan petugas yang melakukan pemilahan sampah dan perencanaan anggaran, sehingga perencanaan pengelolaan Bank Sampah di Kota Mojokerto menjadi lebih baik. Upaya yang dapat dilaksanakan yaitu dengan diadakannya sosialisasi program bank sampah oleh BSI sebagai pusat program bank sampah sehingga dalam perencanaanya untuk melaksanakan bank sampah disetiap RT/RW pada setiap kecamatan dapat berjalan dengan baik. 
Tabel 1

PERENCANAAN PENGELOLAAN BANK SAMPAH

\begin{tabular}{|c|c|c|c|c|c|}
\hline \multirow{2}{*}{ No } & \multirow{2}{*}{ Pertanyaan } & \multicolumn{2}{|c|}{ Hasil Observasi } & \multirow{2}{*}{$\begin{array}{l}\text { Prosentase } \\
(\%)\end{array}$} & \multirow{2}{*}{ Kriteria } \\
\hline & & $\mathrm{Ya}$ & Tidak & & \\
\hline 1 & Pengelolaan bank sampah & 25 & 0 & 100 & Sesuai \\
\hline 2 & Pemilihan sampah & 22 & 3 & 88 & Sesuai \\
\hline 3 & $\begin{array}{l}\text { Jadwal pengelola sampah } \\
\text { padatahap pemilahan sampah }\end{array}$ & 17 & 8 & 68 & Sesuai \\
\hline 4 & $\begin{array}{l}\text { APD saat melakukan pemilahan } \\
\text { sampah }\end{array}$ & 15 & 10 & 60 & Sesuai \\
\hline 5 & $\begin{array}{l}\text { Ketentuan petugas yang } \\
\text { melakukan tahap pemilahan } \\
\text { sampah }\end{array}$ & 5 & 20 & 20 & $\begin{array}{l}\text { Tidak } \\
\text { sesuai }\end{array}$ \\
\hline 6 & $\begin{array}{l}\text { Rincian anggaran dana pada } \\
\text { tahap pemilahan sampah }\end{array}$ & 6 & 19 & 24 & $\begin{array}{l}\text { Tidak } \\
\text { sesuai }\end{array}$ \\
\hline & Total & 90 & 60 & 60 & Sesuai \\
\hline
\end{tabular}

\section{Pengorganisasian dalam pelaksanaan bank sampah}

Tabel 2

PENGORGANISASIAN BANK SAMPAH

\begin{tabular}{|c|c|c|c|c|c|}
\hline \multirow{2}{*}{ No } & \multirow{2}{*}{ Pertanyaan } & \multicolumn{2}{|c|}{ Hasil Observasi } & \multirow{2}{*}{$\begin{array}{l}\text { Prosentase } \\
\text { (\%) }\end{array}$} & \multirow{2}{*}{ Kriteria } \\
\hline & & $\mathrm{Ya}$ & Tidak & & \\
\hline 1 & $\begin{array}{l}\text { Telah terbentuk organisasi bank } \\
\text { sampah sesuai dengan } \\
\text { ketentuan yang berlaku }\end{array}$ & 21 & 4 & 84 & Sesuai \\
\hline 2 & $\begin{array}{l}\text { Tugas atau pembagian tugas } \\
\text { pada tahap pemilahan sampah } \\
\text { bagi petugas yang melakukan } \\
\text { pemilihan sampah }\end{array}$ & 18 & 7 & 72 & Sesuai \\
\hline 3 & $\begin{array}{l}\text { Petugas atau orang yang } \\
\text { melakukan tahap pemilahan } \\
\text { sampah sudah terstruktur dan } \\
\text { terorganisasi }\end{array}$ & 11 & 14 & 44 & $\begin{array}{l}\text { Tidak } \\
\text { sesuai }\end{array}$ \\
\hline 4 & $\begin{array}{l}\text { Penilaian kompetensi petugas } \\
\text { pemilah sampah (misalnya } \\
\text { persyaratan pendidikan) }\end{array}$ & 2 & 23 & 8 & $\begin{array}{l}\text { Tidak } \\
\text { sesuai }\end{array}$ \\
\hline & Total & 52 & 48 & 52 & Sesuai \\
\hline
\end{tabular}

Pengorganisasian pengelolaan bank sampah di Kota Mojokerto masih termasuk dalam kategori sedang, sehingga harus dilakukan perbaikan pada indikator pengorganisasian petugas yang melakukan pemilahan sampah dan penilaian kompetensi petugas, sehingga pengorganisasian pengelolaan Bank Sampah di Kota Mojokerto menjadi lebih baik. Hal ini perlu dilakukan pembinaan dan sosialisasi terkait dengan pelaksanaan dan pengorganisasian dalam pengelolaan bank sampah.

\section{Pelaksanaan Pengelolaan Bank Sampah}

Pelaksanaan pengelolaan bank sampah di Kota Mojokerto sebagian besar termasuk dalam kategori buruk, sehingga harus dilakukan perbaikan pada indikator perincian anggaran, tempat penampungan sampah dan penilaian kompetensi petugas. Upaya tersebut perlu dilaksanakan agar pelaksanaan pengelolaan Bank Sampah di Kota Mojokerto menjadi lebih baik. 
Perlu rapat rutin dan koordinasi untuk mengevaluasi jalannya Bank Sampah dan membahas kendala yang dihadapi oleh petugas Bank Sampah untuk meningkatkan nasabah dan kinerja Bank Sampah, melakukan kerjasama dengan investor dalam hal penambahan modal/pengadaan mesin.

Tabel 3

PELAKSANAAN PENGELOLAAN BANK SAMPAH

\begin{tabular}{|c|c|c|c|c|c|}
\hline \multirow{2}{*}{ No } & \multirow{2}{*}{ Pertanyaan } & \multicolumn{2}{|c|}{ Hasil Observasi } & \multirow{2}{*}{$\begin{array}{c}\text { Prosentase } \\
(\%)\end{array}$} & \multirow{2}{*}{ Kriteria } \\
\hline & & $\mathrm{Ya}$ & Tidak & & \\
\hline 1 & $\begin{array}{l}\text { Pelaksanaan pengelolaan bank } \\
\text { sampah, apakah sesuai dengan } \\
\text { tahapan-tahapannya }\end{array}$ & 19 & 6 & 76 & Sesuai \\
\hline 2 & $\begin{array}{l}\text { Pengelolaan bank sampah } \\
\text { terdapat perencanaan rincian } \\
\text { anggaran dana }\end{array}$ & 5 & 20 & 20 & $\begin{array}{l}\text { Tidak } \\
\text { sesuai }\end{array}$ \\
\hline 3 & Lokasi TPS sudah tersedia & 20 & 5 & 80 & Sesuai \\
\hline 4 & $\begin{array}{l}\text { Tempat penampungan sampah } \\
\text { yang tersedia mencukupi untuk } \\
\text { menampung sampah }\end{array}$ & 8 & 17 & 32 & $\begin{array}{l}\text { Tidak } \\
\text { sesuai }\end{array}$ \\
\hline 5 & $\begin{array}{l}\text { Penilaian kompetensi } \\
\text { bagipetugas penampungan } \\
\text { sampah }\end{array}$ & 6 & 19 & 24 & $\begin{array}{l}\text { Tidak } \\
\text { sesuai }\end{array}$ \\
\hline & Total & 58 & 67 & 46 & $\begin{array}{l}\text { Tidak } \\
\text { Sesuai }\end{array}$ \\
\hline
\end{tabular}

\section{Pengawasan Bank Sampah}

Tabel 4

PENGAWASAN BANK SAMPAH

\begin{tabular}{|c|c|c|c|c|c|}
\hline \multirow{2}{*}{ No } & \multirow{2}{*}{ Pertanyaan } & \multicolumn{2}{|c|}{ Hasil Observasi } & \multirow{2}{*}{$\begin{array}{c}\text { Prosentase } \\
(\%)\end{array}$} & \multirow{2}{*}{ Kriteria } \\
\hline & & $\mathrm{Ya}$ & Tidak & & \\
\hline 1 & $\begin{array}{l}\text { Selama pengelolaan bank } \\
\text { sampah anda selalu diperhatikan } \\
\text { oleh pihak terkait baik vasilitas } \\
\text { maupun lainya }\end{array}$ & 11 & 14 & 44 & $\begin{array}{l}\text { Tidak } \\
\text { sesuai }\end{array}$ \\
\hline 2 & $\begin{array}{l}\text { Ada pengawasan terhadap } \\
\text { pelaksanaan kegiatan } \\
\text { pengumpulan sampah }\end{array}$ & 8 & 17 & 32 & $\begin{array}{l}\text { Tidak } \\
\text { sesuai }\end{array}$ \\
\hline 3 & $\begin{array}{l}\text { Penggunaan APD sudah sesuai } \\
\text { terhadap petugas pada saat } \\
\text { kegiatan pengumpulan sampah }\end{array}$ & 13 & 12 & 52 & sesuai \\
\hline 4 & $\begin{array}{l}\text { Pelaksanaan kegiatan pemilahan } \\
\text { sampah telah dilaksanakan } \\
\text { sesuai dengan perencanaan } \\
\text { yang telah dibuat }\end{array}$ & 11 & 14 & 44 & $\begin{array}{l}\text { Tidak } \\
\text { sesuai }\end{array}$ \\
\hline 5 & $\begin{array}{l}\text { Jumlah petugas atau orang yang } \\
\text { menangani tahap pemilahan } \\
\text { sampah sudah mencukupi }\end{array}$ & 13 & 12 & 52 & Sesuai \\
\hline & Total & 56 & 69 & 45 & $\begin{array}{l}\text { Tidak } \\
\text { sesuai }\end{array}$ \\
\hline
\end{tabular}

Dalam pengawasan pengelolaan bank sampah di Kota Mojokerto sebagian besar termasuk dalam kategori buruk, sehingga harus dilakukan perbaikan 
pada indikator peningkatan pemberian fasilitas dari pihak terkait, pengawasan dan peningkatan kesesuaian antara perencanaan dengan pelaksanaan pengelolaan Bank Sampah. Upaya pengawasan pengelolaan Bank Sampah di
Kota Mojokerto menjadi lebih baik melalui peningkatan Partisipasi masyarakat yaitu pengambilan bagian atau keikutsertaan masyarakat menjadi nasabah pada bank sampah.

\section{Analisis SWOT} berikut :

Hasil pembobotan variabel sebagai acuan perhitungan IFAS adalah sebagai

Tabel 5

MATRIKS IFAS BANK SAMPAH KOTA MOJOKERTO

\begin{tabular}{|c|c|c|c|}
\hline Stregth & Bobot & Rating & $\begin{array}{c}\text { SKOR } \\
\text { (Bobot x } \\
\text { Rating) }\end{array}$ \\
\hline $\begin{array}{l}\text { Proses pemilihan sampah di setiap } \\
\text { kecamatan telah dilakukan dengan baik dan } \\
\text { sesuai dengan ketentuan yang berlaku }\end{array}$ & 0,11 & 3 & 0,330 \\
\hline $\begin{array}{l}\text { Jadwal pengelola sampah padatahap } \\
\text { pemilahan sampah telah dilakukan } \\
\text { ditempat penampungan sampah masing- } \\
\text { masing kecamatan }\end{array}$ & 0,11 & 2 & 0,220 \\
\hline $\begin{array}{l}\text { Telah disediakan APD saat melakukan } \\
\text { pemilahan sampah, diantaranya } \\
\text { menggunakan masker, sarung tangun, } \\
\text { sepatu dll }\end{array}$ & 0,08 & 3,2 & 0,256 \\
\hline $\begin{array}{l}\text { Terdapat ketentuan petugas yang } \\
\text { melakukan tahap pemilahan sampah yang } \\
\text { tersebar di beberapa RT/RW dalam } 1 \text { desa } \\
\text { di seluruh kecamatan di Kota Mojokerto }\end{array}$ & 0,13 & 3 & 0,390 \\
\hline $\begin{array}{l}\text { Rincian anggaran dana pada tahap } \\
\text { pemilahan sampah belum maksimal }\end{array}$ & 0,04 & 3 & 0,120 \\
\hline Sub Total Strenght & 0,47 & 2,84 & 1,316 \\
\hline Weakness & Bobot & Rating & $\begin{array}{c}\text { Skor } \\
\text { (Bobot x } \\
\text { Rating) }\end{array}$ \\
\hline $\begin{array}{l}\text { Selama pengelolaan bank sampah apakah } \\
\text { telah terbentuk bank sampah }\end{array}$ & 0,05 & 2,3 & 0,115 \\
\hline $\begin{array}{l}\text { Organisasi bank sampah sesuai dengan } \\
\text { ketentuan yang berlaku }\end{array}$ & 0,12 & 2,5 & 0,300 \\
\hline $\begin{array}{l}\text { Apakah ada uraian tugas atau pembagian } \\
\text { tugas pada tahap pemilahan }\end{array}$ & 0,05 & 2,4 & 0,120 \\
\hline $\begin{array}{l}\text { Petugas atau orang yang melakukan tahap } \\
\text { pemilahan sampah sudah terstruktur dan } \\
\text { terorganisasi }\end{array}$ & 0,11 & 2,2 & 0,242 \\
\hline $\begin{array}{l}\text { Apakah ada penilaian kompetensi petugas } \\
\text { pemilah sampah (misalnya persyaratan } \\
\text { pendidikan) }\end{array}$ & 0,15 & 2,9 & 0,435 \\
\hline $\begin{array}{l}\text { Pemilahan sampah bagi petugas yang } \\
\text { melakukan pemilahan sampah }\end{array}$ & 0,05 & 2,98 & 0,149 \\
\hline Sub Total Weakness & 0,53 & 2,596 & 1,361 \\
\hline Total IFAS & 1 & 2,718 & 2,677 \\
\hline
\end{tabular}


Langkah selanjutnya yaitu nilai total skor dari masing-masing faktor dapat dirincikan Strength 1,316 Weakness 1,361. Opportunity 1,730440232 danTreath 1,147155115 . maka diketahui selisih total skor faktor Strenght dan Weakness (-) 0,045 . sedangkan selisih total skor faktor Opportunity dan Treath $(+)$ 0,583 di bawah ini merupakan gambar diagram Cartesius Analisis SWOT yang dapat digunakan untuk menentukan posisi bank sampah berada di kuadran berapa sehingga dapat ditentukan strategi yang paling tepat yang harus diterapkan oleh bank sampah untuk keberlanjutannya.

opportunity

$(1,730440232)$

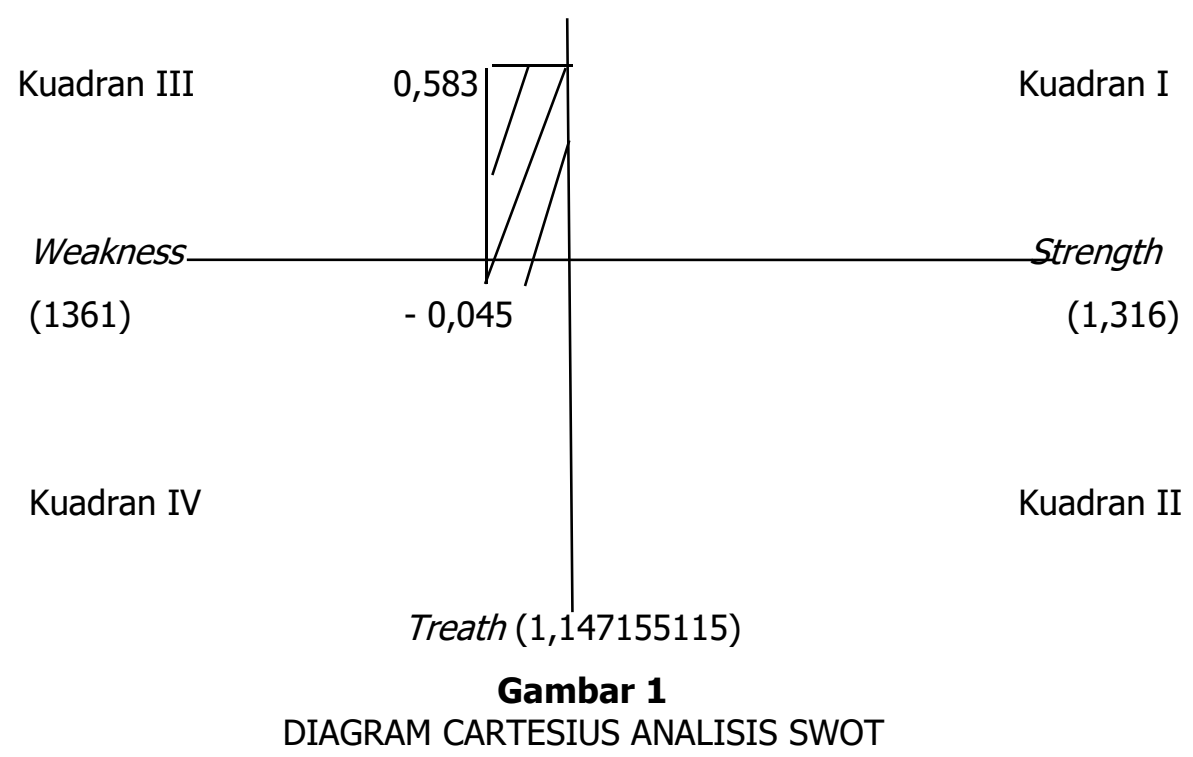

Berdasarkan analisis SWOT terhadap faktor internal dan eksternal diperoleh koordinat kebijakan pengembangan bank sampah berada di kuadran III (negatif,positif) seperti terlihat pada Gambar 1. Rekomendasi strategi yang diberikan adalah Ubah Strategi, artinya organisasi disarankan untuk mengubah strategi sebelumnya. Sebab, strategi yang lama sulit untuk dapat menangkap peluang sekaligus memperbaiki kinerja organisasi.

\section{KESIMPULAN}

Manajemen pengelolaan bank sampah di 3 (tiga) kecamatan kota Mojokerjo memiliki perencanaan, pengorganisasian dan pelaksanaan sebagian besar belum sesuai, dengan nilai $56 \%$ sedangkan pada tahap Pengawasan sebagian besar sudah sesuai dengan niai $52 \%$. Berdasarkan Peraturan Menteri Lingkungan Hidup Republik
Indonesia No. 13 Tahun 2012 tentang Pedoman Pelaksanaan Reduce, Reuse dan Recycle melalui Bank Sampah. Hasil SWOT masuk di kuadran III nilai Weakness adalah - 0,045 dan Nilai Oppotunity adalah 0,583, sehingga alternatif strategi yang dapat diterapkan adalah : Strategi WO (WeaknessOpportunity). Strategi ini merupakan gabungan dari faktor internal weakness dengan faktor eksternal opportunity, strategi ini diterapkan berdasarkan pemanfaatan peluang yang ada dengan cara mengurangi kelemahan yang dimiliki oleh bank sampah.

\section{SARAN}

Upaya perencanaan bank sampah yang dapat dilaksanakan yaitu dengan diadakannya sosialisasi program bank sampah oleh BSI sebagai pusat program bank sampah sehingga dalam perencanaanya untuk melaksanakan 
bank sampah disetiap RT/RW pada setiap kecamatan dapat berjalan dengan baik. Pengorganisasian pelaksanaan bank sampah perlu dilakukan pembinaan dan sosialisasi terkait dengan pelaksanaan dan pengorganisasian dalam pengelolaan bank sampah.

\section{DAFTAR PUSTAKA}

Apriliyanti, 2015.Evaluasi Kinerja Bank Sampah Kartini Mandiri Desa Pesanggrahan Kota Batu.Jurnal Pembangunan dan Alam Lestari,(Vol. , No. 2, 2015) : $143-$ 152.

Ardyan, Rachmat, 2013. Evaluasi Pelaksanaan Pengelolaan Sampah di Bank Sampah Kecamatan Sukun Kota Malang. Gema Kesehatan Lingkungan, (Vol. XI. No. 3) : 139143.

Chrysantin.2013. Sustainable solid waste management practices and perceived cleanliness in a low-income city. Habitat International,

Juliandoni,2013.Pelaksanaan Bank Sampah Dalam Sistem. Pengelolaan Sampah di Kelurahan Gunung Bahagia Balikpapan.

Kock\&Domina, 2009. A Comparative Study of Municipal Solid Waste
Management in India and Japan.The Gakken Research Papers, 2015.

Mardikanto, T dan Soebianto, P. 2015. Pemberdayaan Masyarakat dalam Perspektif dan Kebijakan Publik. Bandung : PT. Alfabeta.

Notoatmodjo(2010.IImu Perilaku Kesehatan. Jakarta: PT Rineka Cipta.

Notoatmodjo,2007.Promosi kesehatan dan ilmu perilaku. Rineka cipta : Jakarta.

Novianty,2012.Manfaat Pengelolaan Sampah Terpadu, Surakarta: CV. Aryhaeko Sinergi Persada;

Solehati. 2005. Studi tentang Pengelolaan Sampah Padat Rumah Tangga di Kota Meulaboh Aceh. [Tesis].Bogor Institut Pertanian Bogor.

Sugiyono, 2013. Metode Penelitian Administrasi. Bandung :

Wijaya,2010.Dampak pengurangan subsidi BBM terhadap kondisi ekonomi masyarakat.

Zakianis et al.,2018. Penanganan dan Pengolahan Sampah. Jakarta: Penebar Swadaya 